\title{
Apixaban for Secondary Stroke Prevention: Coexistant Cerebral Atherosclerosis May Increase Recurrent Strokes
}

\author{
Jong S. Kim, ${ }^{\mathrm{a}}$ Jaseong Koo, ${ }^{\mathrm{b}}$ Dong-Ick Shin, ${ }^{\mathrm{c}}$ Byung-Su Kim, ${ }^{\mathrm{d}}$ Jei Kim, ${ }^{\mathrm{e}}$ Eung-Gyu Kim, ${ }^{\mathrm{f}}$ Keun-Sik Hong, ${ }^{\mathrm{g}}$ \\ Hyeju $\mathrm{Yi}^{\mathrm{h}}$

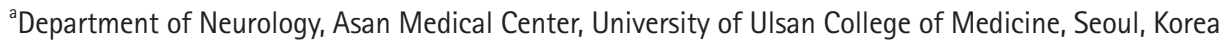 \\ ${ }^{b}$ Department of Neurology, Seoul St. Mary's Hospital, College of Medicine, The Catholic University of Korea, Seoul, Korea \\ 'Department of Neurology, Chungbuk National University Hospital, Chungbuk National University College of Medicine, Cheongju, Korea \\ ${ }^{\mathrm{d} D}$ Department of Neurology, Bundang Jesaeng General Hospital, Daejin Medical Center, Seongnam, Korea \\ e Department of Neurology, Chungnam National University Hospital, Chungnam National University College of Medicine, Daejeon, Korea \\ fDepartment of Neurology, Inje University Busan Paik Hospital, College of Medicine, Inje University, Busan, Korea \\ ${ }^{9}$ Department of Neurology, Inje University Ilsan Paik Hospital, College of Medicine, Inje University, Goyang, Korea \\ ${ }^{\text {h}}$ Bristol Myers Squibb Korea, Seoul, Korea
}

Background and Purpose Oral anticoagulants are needed in stroke patients with atrial fibrillation (AF) for the prevention of recurrent stroke. However, the risk of major events or bleeding may be greater in stroke patients than in those without, because the presence of cerebral atherosclerosis or small vessel disease may increase these risks. This study aimed to investigate the outcomes of apixaban-treated stroke patients with AF and assess whether these factors are associated with the outcome.

Methods This was a sub-analysis of stroke patients with AF enrolled in a prospective, open-label, multicenter, post-marketing surveillance study in South Korea, who were treated with apixaban and underwent magnetic resonance imaging (MRI) (Clinical trial registration: NCT01885598).

Results A total of 651 patients (mean age, $72.5 \pm 8.7$ years) received apixaban for a mean duration of $82.7 \pm 37.4$ weeks. Fifty-three bleeding events occurred in 39 patients (6.0\%), and $10(1.5 \%)$ experienced major bleeding. Seventeen patients (2.6\%) had major events (stroke, $n=15,2.3 \%$; all ischemic), systemic embolism $(n=1,0.2 \%)$, and death $(n=3,0.5 \%)$. MRI data showed no significant association between white matter ischemic changes and microbleeds, and major events or bleeding. Patients with cerebral atherosclerotic lesions had a higher rate of major events than those without $(4.6 \%[n=10 / 219]$ vs. $1.7 \%[n=7 / 409], P=0.0357)$, which partly explains the increased prevalence of major outcomes in this group versus patients without stroke $(0.7 \%, P=0.0002)$.

Conclusions Apixaban is generally safe for patients with ischemic stroke. Increased primary outcomes in stroke patients may in part be attributed to the presence of cerebral atherosclerotic lesions, suggesting that further studies are needed to establish therapeutic strategies in this population.
Correspondence: Jong S. Kim

Department of Neurology, Asan Medical Center, University of Ulsan College of

Medicine, 88 Olympic-ro 43-gil, Songpagu, Seoul 05505, Korea

Tel: +82-2-3010-3440

Fax: +82-2-474-4691

E-mail: jongskim@amc.seoul.kr https://orcid.org/0000-0002-3999-4992

Received: July 2, 2021

Revised: November 13, 2021

Accepted: November 19, 2021

Keywords Apixaban; Stroke; Magnetic resonance imaging

Copyright @ $\odot 2022$ Korean Stroke Society

This is an Open Access article distributed under the terms of the Creative Commons Attribution Non-Commercial License (http://creativecommons.org/licenses/by-nc/4.0/) which permits unrestricted non-commercial use, distribution, and reproduction in any medium, provided the original work is properly cited. 


\section{Introduction}

Owing to their superior safety profiles, non-vitamin $\mathrm{K}$ antagonist oral anticoagulants (NOACs) have recently replaced warfarin for the reduction of stroke and systemic embolism risk in patients with non-valvular atrial fibrillation (AF). International guidelines now recommend NOACs as a first-line treatment option for the management of AF patients. ${ }^{1,2}$ In a phase 3 , multicenter, double-blind, randomized trial of more than 18,000 patients with AF (Apixaban for Reduction in Stroke and Other Thromboembolic Events in Atrial Fibrillation [ARISTOTLE]), the factor Xa inhibitor apixaban was superior to warfarin in reducing the risk of stroke or systemic embolism and of major bleeding, and was associated with significantly lower all-cause mortality. ${ }^{3}$ Similar results were obtained in a sub-analysis of around 2,000 ARISTOTLE patients from East Asia. ${ }^{4}$

In 2013, apixaban received regulatory approval in South Korea for stroke and systemic embolism risk reduction in patients with $\mathrm{AF}$ aged $\geq 18$ years. The current indication includes all adult patients with non-valvular AF. The approved oral dose is $5 \mathrm{mg}$ twice daily (BID), while a dose reduction to $2.5 \mathrm{mg}$ BID is recommended in patients with $\geq 2$ of the following characteristics: age $\geq 80$ years, body weight $\leq 60 \mathrm{~kg}$, or serum creatinine $\geq 1.5 \mathrm{mg} / \mathrm{dL}$. Patients with a creatinine clearance of 15 to 29 $\mathrm{mL} / \mathrm{min}$ should receive a lower dose (2.5 mg BID), and apixaban is not recommended for those with creatinine clearance $<15$ $\mathrm{mL} / \mathrm{min}$.

Following the original marketing authorization, a key requirement of the Korean Ministry of Food and Drug Safety is that safety and effectiveness should be assessed in the setting of routine practice. Consequently, a regulatory post-marketing surveillance (PMS) study was conducted. In patients who experience a stroke associated with $A F$, anticoagulant therapy is recommended. ${ }^{5}$ Compared with warfarin, NOACs reduce the risk of recurrent stroke, death, and major bleeding in these individuals. ${ }^{6}$ However, the presence of stroke may increase the risk of subsequent (ischemic or hemorrhagic) stroke events. In a Japanese PMS study of apixaban, 17\% of patients received the drug as secondary prevention, and the incidence of hemorrhagic and thromboembolic events was higher than in those without a history of stroke. ${ }^{7}$ In patients with stroke, the presence of cerebral arterial atherosclerosis or cerebral small vessel disease (SVD) manifesting as white matter hyperintensities (WMH) or microbleeds may lead to increased stroke recurrence rates, ${ }^{8}$ even in patients receiving anticoagulation. To the best of the authors' knowledge, these issues have not been investigated in previous studies on apixaban.

This study aimed to investigate the outcomes of patients with AF-related stroke who were treated with apixaban, and to examine whether the presence of cerebral artery atherosclerosis or SVD influences these outcomes. For this purpose, a subgroup analysis was conducted of patients with stroke who underwent brain magnetic resonance imaging (MRI) as part of the standard of care from the PMS study.

\section{Methods}

\section{Study design and patients}

This was a sub-study of a large prospective, open-label, non-interventional, non-controlled, multicenter, observational PMS study of patients treated with apixaban as part of routine care between November 2011 and November 2017 in South Korea. Patients aged $\geq 18$ years, diagnosed with non-valvular $A F$, and received apixaban therapy for the first time to reduce the risk of stroke and systemic embolism were eligible for this study. Investigators were required to use an electronic case report form to record the AF information, including the date of diagnosis, type of $A F$, symptoms of $A F$, and pulse rate, which were based on the patients' medical records. AF duration was calculated as '(the informed consent date-the date of nonvalvular AF diagnosis+1)/365.25.

Key exclusion criteria were as follows: prior treatment with apixaban; clinically significant active bleeding; coagulopathy associated with hepatic disease and clinically relevant bleeding risk; increased bleeding risk due to specific underlying diseases/ conditions (recent gastrointestinal ulceration, recent intracranial hemorrhage, intraspinal or intracerebral vascular abnormalities, recent brain, spinal or ophthalmic surgery history, recent brain or spinal injury, known esophageal varices, large [ $>5$ $\mathrm{mm}$ ] cerebral aneurysms, malignant neoplasms with high risk of bleeding); or concomitant treatment with any other anticoagulant agent. The follow-up period was 24 months.

For this study, the principal investigators of 37 out of 56 participating sites belonging to the Department of Neurology were asked of the following: (1) to participate in this substudy; (2) whether the patients had symptomatic ischemic stroke; and (3) whether multimodal MRI was routinely used, including diffusion-weighted imaging (DWI), fluid-attenuated inversion recovery (FLAIR), gradient echo imaging (GRE), and magnetic resonance (MR) angiography. Ultimately, 21 sites agreed to participate (Figure 1).

Prior to patient enrollment, the writing committee members established an additional three-page data sheet that included the location of the relevant ischemic lesion detected by DWI at the time of enrollment, presence and degree of WMH on FLAIR (Fazekas scale), ${ }^{9}$ presence and number of microbleeds by GRE, 


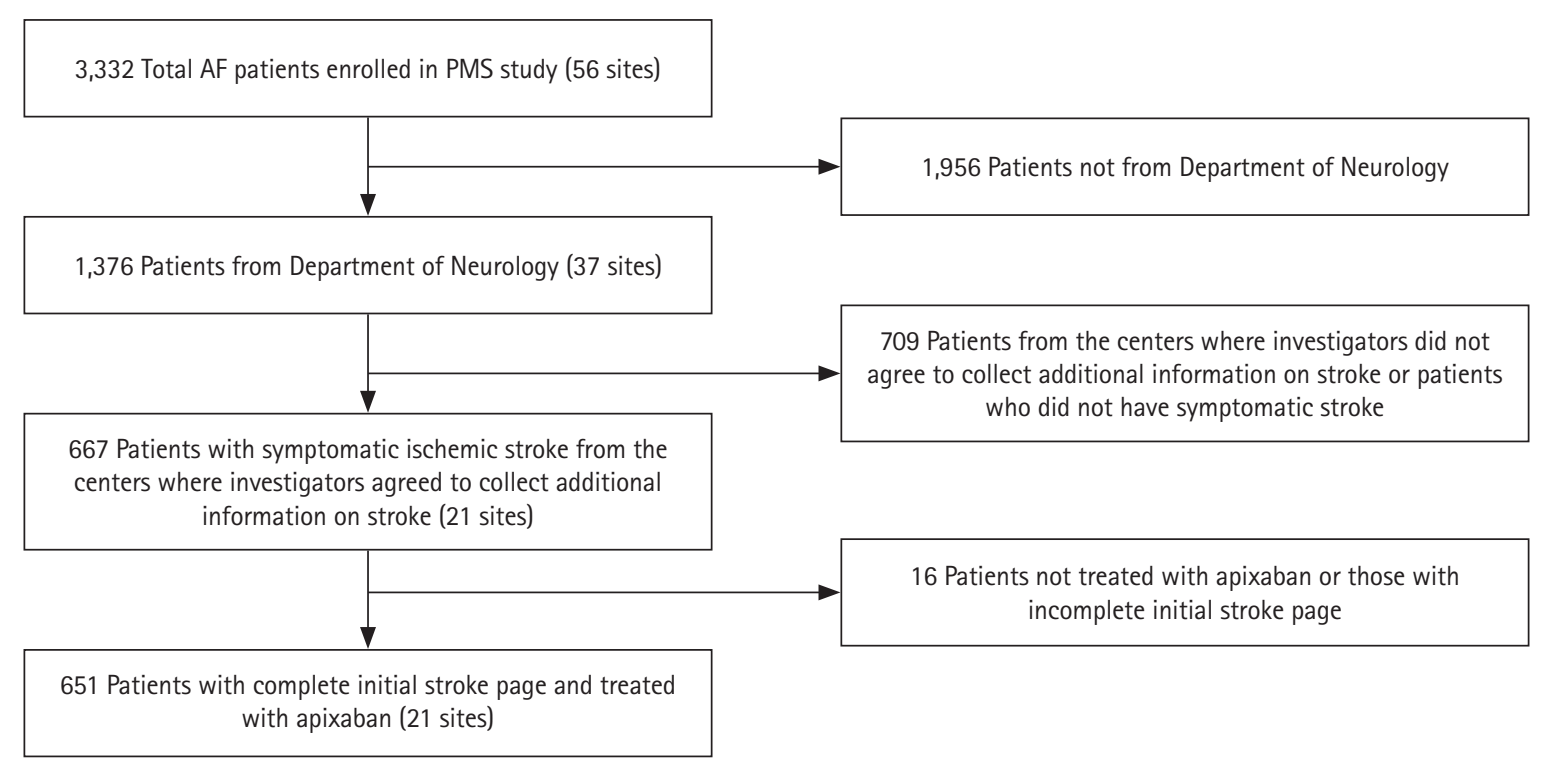

Figure 1. Patient flowchart. AF, atrial fibrillation; PMS, post-marketing surveillance.

and presence of cerebral atherosclerosis and aneurysm by angiography (computed tomography or MR angiography, or transfemoral cerebral angiography) (Appendix 1). The diagnosis of cerebral atherosclerosis was made based on the reading of a neuroradiologist in each center, without using criteria based on the degree of stenosis. The same information was obtained at the time of recurrent stroke in patients who developed recurrent strokes during the study period. The MRI protocol (either 1.5T or 3.0T) was not centralized, and the data used in routine clinical practice were obtained from each center. In addition, echocardiographic findings were recorded (if performed at the time of stroke or $<3$ months before stroke onset). All events after apixaban treatment were recorded, including hemorrhage and ischemic stroke. The possibility of the lesion being caused by mechanisms other than cardiac embolism (e.g., large artery disease or SVD) was also documented (Appendix 1).

Most patients were treated based on the approved doses of apixaban at 2.5 or $5 \mathrm{mg}$ orally BID. However, off-label dosing was allowed based on clinical judgment. Treatment could be discontinued at any time at the discretion of the investigator. The study was conducted in accordance with the Declaration of Helsinki, the International Society for Pharmacoepidemiology Guidelines for Good Pharmacoepidemiology Practices, and other regulatory requirements. Approval was granted at individual sites by local ethics committees, independent review committees, regulatory authorities, and/or other government bodies. All subjects provided written consent prior to enrollment. The trial was registered at clinicaltrials.gov (Clinical trial registration: https://clinicaltrials.gov/ct2/show/NCT01885598; Unique identifier: NCT01885598).

\section{Assessments}

Follow-up visits were scheduled at 3, 6, 12, and 24 months after enrollment. Patient medical records were the data sources for the study variables. Baseline assessments included sex, age, body weight, blood pressure, serum creatinine, creatinine clearance, smoking history, and AF type and duration. MRI data were obtained as described above. During the study period, the apixaban dose and treatment duration were recorded. All instances of major bleeding, defined as any bleeding event that necessitated temporary or permanent apixaban discontinuation or dose reduction, were documented. Major events, defined as stroke of any type, systemic embolism, or death, were also recorded. Detailed information on recurrent stroke was captured on an additional three-page data sheet by the investigators (Appendix 1). Exploratory analyses were also undertaken to compare the rates of major events and major bleeding in the present subgroup of patients versus those without symptomatic ischemic stroke from the same Korean PMS study.

\section{Statistical analyses}

Statistical analyses were performed using SAS, release 9.3 or higher (SAS Institute Inc., Cary, NC, USA). Descriptive statistics were provided, including mean \pm standard deviation and range for continuous variables, and frequency and percentage for categorical variables. Associations between apixaban dosing regimen and rates of major events or major bleeding were assessed using Fisher's exact test. Those between baseline characteristics or imaging findings and rates of major events or major bleeding were assessed using either Fisher's exact test or the chi-square test. Statistical significance was set at $P<0.05$. 


\section{Results}

\section{Baseline characteristics}

Case report forms were collected from apixaban-treated subjects enrolled in the study. The present analysis included data from 651 patients with AF and ischemic stroke assessed using brain MRI. Baseline characteristics are shown in Table 1. Two hundred seventy patients (41.5\%) were female, and the mean age was $72.5 \pm 8.7$ years (range, 40 to 94 ). Many had vascular risk factors, including hypertension $(n=444,68.2 \%)$, diabetes $(n=146,22.4 \%)$, dyslipidemia $(n=230,35.3 \%)$, and smoking $(n=118,18.1 \%)$. Statins were co-administered to 455 patients (69.9\%). In a total of 651 patients (including one patient with missing AF information), 251 (38.6\%) were diagnosed with AF after stroke; among the remainder, $110(16.9 \%)$ had paroxysmal AF, and 289 (44.4\%) had persistent AF. The mean AF duration was $2.8 \pm 3.8$ years (range, 0 to 23.0 ).

MRI findings showed that $64.3 \%$ of the patients had WMH changes (Fazekas grade 1, 42.2\%; grade 2, 14.7\%; grade 3, $7.4 \%)$. A total of 82 patients (13.3\%) had microbleeds. Nineteen $(3.1 \%)$ and $63(10.2 \%)$ patients had $\geq 5$ and $<5 \mathrm{mi}-$ crobleeds, respectively. Nineteen patients (3.0\%) had aneurysms ( $\leq 5 \mathrm{~mm}$ ). Two hundred nineteen patients $(34.9 \%)$ had cerebral atherosclerotic lesions, with 151 having intracranial atherosclerosis, 41 having extracranial atherosclerosis, and 58 having both (Table 2).

The apixaban dose was recorded in 649 patients (Table 1). Apixaban 5 mg BID was prescribed to 488 subjects (75.2\%) and apixaban $2.5 \mathrm{mg}$ BID in 95 subjects (14.6\%). Thus, 583 individuals (89.8\%) received an on-label dose. The remaining 66 patients were treated with either an off-label reduced dose of $2.5 \mathrm{mg} \mathrm{BID}(\mathrm{n}=59,9.1 \%)$ or an off-label increased dose greater than the standard dose $(n=7,1.1 \%)$. Treatment was administered for a mean of $82.7 \pm 37.4$ weeks (range, 0.1 to 126.0 ).

\section{Outcomes}

Fifty-three adverse events of bleeding were recorded in 39 patients (6.0\%). Ten patients (1.5\%) experienced major bleeding (without intracerebral hemorrhage), leading to complete or temporary discontinuation of apixaban in two and three patients, respectively, and a dose reduction in six cases. In total, 17 patients (2.6\%) experienced major events during the follow-up period. Fifteen (2.3\%) developed a stroke (all were ischemic), one (0.2\%) had a systemic embolism, and three (0.5\%) expired (Table 3). Among the three mortalities, two were 'stroke-related deaths' and one was 'cardiovascular disease-related death. The rate of major bleeding was higher in patients with hypertension than in those without hypertension

Table 1. Baseline characteristics

\begin{tabular}{|c|c|}
\hline Characteristic & Patients $(n=651)$ \\
\hline Female ex & $270(41.5)$ \\
\hline Age (yr) & $72.5 \pm 8.7(40-94)$ \\
\hline Body weight $(\mathrm{kg})(\mathrm{n}=571)$ & $62.9 \pm 11.4(34-98)$ \\
\hline Creatinine clearance $(\mathrm{mL} / \mathrm{min})(\mathrm{n}=568)$ & $64.2 \pm 23.0(14.2-151.5)$ \\
\hline Hypertension & $444(68.2)$ \\
\hline Diabetes & $146(22.4)$ \\
\hline Dyslipidemia & $230(35.3)$ \\
\hline Current smoker & $118(18.1)$ \\
\hline Statin co-administered & $455(69.9)$ \\
\hline Duration of AF (yr) $(n=475)$ & $2.8 \pm 3.8(0-23.0)$ \\
\hline Left ventricular ejection fraction $(\%)(n=461)$ & $59.8 \pm 10.4(16.0-86.0)$ \\
\hline Valvular abnormality* $(n=463)$ & $216(46.7)$ \\
\hline \multicolumn{2}{|l|}{ Apixaban dose $(n=649)$} \\
\hline On-label standard dose (5 mg BID) & $488(75.2)$ \\
\hline On-label reduced dose (2.5 mg BID) & $95(14.6)$ \\
\hline Off-label reduced dose & $59(9.1)$ \\
\hline Off-label increased dose & $7(1.1)$ \\
\hline Duration of apixaban treatment (wk) $(n=578)$ & $82.7 \pm 37.4(0.1-126.0)$ \\
\hline
\end{tabular}

Values are presented as number (\%) or mean \pm standard deviation (range).

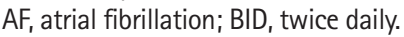

${ }^{*}$ Mitral or aortic valve regurgitation/stenosis. 
Table 2. MRI findings and major events or major bleeding

\begin{tabular}{|c|c|c|c|c|c|c|}
\hline MRI finding & Total patients & Major events* & Stroke & Systemic embolism & Death & Major bleeding \\
\hline \multicolumn{7}{|c|}{ White matter ischemic change, Fazekas scale $(n=580)$} \\
\hline 0 & 207 & $6(2.9)$ & $6(2.9)$ & $0(0)$ & $2(1.0)$ & $3(1.4)$ \\
\hline 1 & 245 & $7(2.9)$ & $6(2.4)$ & $1(0.4)$ & $0(0)$ & $6(2.4)$ \\
\hline 2 & 85 & $1(1.2)$ & $1(1.2)$ & $0(0)$ & $0(0)$ & $1(1.2)$ \\
\hline 3 & 43 & $2(4.7)$ & $2(4.7)$ & $0(0)$ & $0(0)$ & $0(0)$ \\
\hline$P^{+}$ & - & 0.6577 & 0.6422 & 1.0000 & 0.5200 & 0.7859 \\
\hline \multicolumn{7}{|c|}{ Microbleeds ( $n=615)$} \\
\hline Yes $(\geq 5)$ & 19 & $0(0)$ & $0(0)$ & $0(0)$ & $0(0)$ & $0(0)$ \\
\hline Yes $(<5)$ & 63 & $3(4.8)$ & $2(3.2)$ & $1(1.6)$ & $0(0)$ & $1(1.6)$ \\
\hline No & 533 & $13(2.4)$ & $13(2.4)$ & $0(0)$ & $2(0.4)$ & $7(1.3)$ \\
\hline$P^{+}$ & - & 0.4342 & 0.7928 & 0.1333 & 1.0000 & 0.6840 \\
\hline \multicolumn{7}{|l|}{ Aneurysm ( $n=629)$} \\
\hline Yes & 19 & $0(0)$ & $0(0)$ & $0(0)$ & $0(0)$ & $0(0)$ \\
\hline No & 610 & $17(2.8)$ & $15(2.5)$ & $1(0.2)$ & $3(0.5)$ & $10(1.6)$ \\
\hline$P^{+}$ & - & 1.0000 & 1.0000 & 1.0000 & 1.0000 & 1.0000 \\
\hline \multicolumn{7}{|c|}{ Atherosclerotic arterial lesion $(n=628)$} \\
\hline Yes & 219 & $10(4.6)$ & $9(4.1)$ & $0(0)$ & $1(0.5)$ & $4(1.8)$ \\
\hline Intracranial & 120 & $4(3.3)$ & $4(3.3)$ & $0(0)$ & $0(0)$ & $1(0.8)$ \\
\hline Extracranial & 41 & $3(7.3)$ & $2(4.9)$ & $0(0)$ & $1(2.4)$ & $1(2.4)$ \\
\hline Both & 58 & $3(5.2)$ & $3(5.2)$ & $0(0)$ & $0(0)$ & $2(3.5)$ \\
\hline No & 409 & $7(1.7)$ & $6(1.5)$ & $1(0.2)$ & $2(0.5)$ & $6(1.5)$ \\
\hline$P$ & - & $0.0357^{\neq}$ & $0.0387^{+}$ & $1.0000^{\dagger}$ & $1.0000^{+}$ & $0.7454^{\dagger}$ \\
\hline
\end{tabular}

Values are presented as number (\%).

$\mathrm{MRI}$, magnetic resonance imaging.

${ }^{*}$ Stroke, systemic embolism, or death; ${ }^{\dagger}$ Fisher's exact test; ${ }^{*}$ Chi-square test.

Table 3. Bleeding and major events (total events=53)

\begin{tabular}{lc}
\hline Variable & No. of patients (\%) \\
\hline Bleeding (adverse event) & $39(6.0)$ \\
Major bleeding & $10(1.5)$ \\
Major events & \\
All & $17(2.6)$ \\
Stroke & $15(2.3)$ \\
Systemic embolism & $1(0.2)$ \\
Death & $3(0.5)$ \\
\hline
\end{tabular}

(2.3\% [n=10/444] vs. $0.0 \%[n=0 / 207]$, respectively; $P=0.0354)$. Otherwise, no significant associations were observed between the rates of major events (and of stroke, systemic embolism, or death analyzed separately) and key baseline characteristics (sex, age, hypertension, diabetes, dyslipidemia, and smoking).

Although MRI was performed in all 15 patients who developed recurrent stroke, the status was evaluable in 13 individuals (Table 4). DWI showed a single lesion in five patients and multiple scattered lesions in another five patients. The number of microbleeds increased in one patient, and GRE showed hemorrhagic transformation in two patients. It was considered possible that large artery disease or SVD may have caused recurrent stroke in four patients and one patient, respectively. Three out of four patients (75.0\%) who had recurrent strokes potentially caused by large artery disease had evidence of atherosclerosis on MR angiography, whereas five of the nine patients (55.6\%) considered to have experienced recurrent strokes caused by cardiogenic embolism had atherosclerotic evidence on the MR angiography. The difference was not statistically significant $(P=0.0930)$.

\section{Association between MRI findings and major events or bleeding}

An analysis of MRI data demonstrated no significant association between $\mathrm{WMH}$, microbleeds, or aneurysm and rates of major events (stroke, systemic embolism, or death) or major bleeding (Table 2). However, patients with cerebral atherosclerotic lesions at baseline (23 missing) had a higher rate of major events than those without $(4.6 \%[n=10 / 219]$ vs. $1.7 \%[n=7 / 409]$, 
Table 4. MRI results and possible stroke pathogenesis in evaluable patients who developed recurrent stroke

\begin{tabular}{|c|c|}
\hline MRI results & Patients $(n=13)$ \\
\hline \multicolumn{2}{|l|}{ DWI } \\
\hline Single lesion (corticosubcortical) & 1 \\
\hline Single lesion (cortical) & 3 \\
\hline Single lesion (subcortical or brainstem $[\leq 15 \mathrm{~mm}]$ ) & 1 \\
\hline Single lesion (subcortical or brainstem $[>15 \mathrm{~mm}]$ ) & 0 \\
\hline Multiple scattered (1 vessel territory) & 3 \\
\hline Multiple scattered ( $>1$ vessel territory) & 2 \\
\hline Missing data & 3 \\
\hline \multicolumn{2}{|l|}{$\mathrm{GRE}^{*}$} \\
\hline \multicolumn{2}{|l|}{ Have 'microbleeds' increased from previous image? } \\
\hline Yes & 1 \\
\hline No & 11 \\
\hline Missing data & 1 \\
\hline \multicolumn{2}{|l|}{ Stroke pathogenesis } \\
\hline \multicolumn{2}{|l|}{$\begin{array}{l}\text { Is it possible that the stroke event was caused by } \\
\text { large-artery disease? }\end{array}$} \\
\hline Yes & 4 \\
\hline No & 9 \\
\hline \multicolumn{2}{|l|}{$\begin{array}{l}\text { Is it possible that the stroke event was caused by } \\
\text { small-vessel disease? }\end{array}$} \\
\hline Yes & 1 \\
\hline No & 12 \\
\hline \multicolumn{2}{|l|}{ Cerebral artery atherosclerosis at baseline MRI } \\
\hline Yes & 8 \\
\hline Intracranial & 4 \\
\hline Extracranial & 1 \\
\hline Both & 3 \\
\hline No & 5 \\
\hline
\end{tabular}

$\mathrm{MRI}$, magnetic resonance imaging; DWI, diffusion-weighted imaging; GRE, gradient-recalled echo.

${ }^{*}$ GRE identified two cases of hemorrhagic transformation.

respectively; $P=0.0357)$. This effect was driven primarily by an increased rate of stroke ( $4.1 \%[n=9 / 219]$ vs. $1.5 \%[n=6 / 409]$, respectively; $P=0.0387$ ). Although major events and strokes were most often observed in patients with both intracranial and extracranial atherosclerosis, followed by those with extracranial atherosclerosis and then those with intracranial atherosclerosis, the small number of outcomes in each group did not allow analysis for statistical difference (Table 2). The rates of systemic embolism, death, or major bleeding did not significantly differ based on the presence of atherosclerotic lesion. Among 219 patients with cerebral atherosclerotic lesion, an antiplatelet agent was administered in 41 patients (18.7\%): 14.2\% (17/120), 29.3\% (12/41), and $20.7 \%(12 / 58)$ in the intracranial, extracranial, and both groups, respectively.

There were no significant associations between overall rates of major events (stroke, systemic embolism, or death assessed separately), rates of major bleeding, and patients' left ventricular ejection fraction ( $\leq 30 \%$ vs. $>30 \%$ ) or valvular abnormalities (present vs. absent) on echocardiography (data not shown).

\section{Apixaban dosing}

Major bleeding rates were significantly higher in individuals receiving off-label reduced-dose apixaban ( $n=7 / 59,11.9 \%)$ than in those receiving on-label standard dose $(n=1 / 488$, $0.2 \%)$, on-label reduced dose $(n=2 / 95,2.1 \%)$, or off-label increased dose $(n=0 / 7,0 \%)(P<0.0001)$.

Of the 16 patients who experienced a major event and for whom there was information regarding the prescribed dose, nine received on-label apixaban standard dose (5 mg BID), five were given on-label reduced dose (2.5 mg BID), and two received an off-label reduced dose. None of the 16 patients received an off-label increased dose. Hence, the rates of major events were $1.8 \%(n=9 / 488)$ in the on-label standard-dose group, $5.3 \%(n=5 / 95)$ in the on-label reduced dose group, $3.4 \%(n=2 / 59)$ in the off-label reduced dose group, and $0 \%$ $(n=0 / 7)$ in the off-label increased dose group $(P=0.2029)$. Among the mortalities, two occurred in patients receiving on-label reduced-dose apixaban $(n=2 / 95,2.1 \%)$, while one received off-label reduced dose ( $n=1 / 59,1.7 \%)$. No deaths were recorded in the other two dosing groups $(P=0.0197)$.

\section{Comparison of event rates between enrolled patients with symptomatic strokes and those without}

Exploratory analyses were performed to compare the rates of major bleeding and major events in the present subgroup of patients (with a symptomatic ischemic stroke) versus another subgroup of patients enrolled in the same study who had no symptomatic ischemic stroke $(n=1,711)$. Patients with stroke were significantly older and showed higher rates of dyslipidemia and cigarette smoking than those without. The rate of major events was also higher in patients with stroke than in those without $(2.6 \%[n=17 / 651]$ vs. $0.7 \%$ [ $n=12 / 1711]$, respectively; $P=0.0002)$. This effect was driven primarily by an increased rate of stroke $(2.3 \%[n=15 / 651]$ vs. $0.5 \%[n=9 / 1,711]$, respectively; $P=0.0001)$. Rates of other major events or major bleeding did not differ between the two groups (Table 5). When patients with cerebral artery atherosclerosis were removed from the group with ischemic stroke, the statistical significance of the increased rates of major events or stroke (vs. those with no history of stroke) disappeared even if patients 
Table 5. Comparison of major events and major bleeding between patients with symptomatic ischemic stroke and those without

\begin{tabular}{|c|c|c|c|}
\hline Characteristic & $\begin{array}{l}\text { Patients with symptomatic ischemic stroke } \\
\text { (Department of Neurology, } n=651 \text { ) }\end{array}$ & $\begin{array}{l}\text { Patients without symptomatic ischemic stroke } \\
\text { (Department of Cardiology, } n=1,711 \text { ) }\end{array}$ & $P$ \\
\hline Age (yr) & $72.5 \pm 8.7$ & $70.0 \pm 10.4$ & $<0.0001^{*}$ \\
\hline Male sex & $381(58.5)$ & $965(56.4)$ & $0.3587^{+}$ \\
\hline Current smoking, yes & $118(18.1)$ & $248(14.5)$ & $0.0306^{\dagger}$ \\
\hline Diabetes, yes & $146(22.4)$ & $444(26.0)$ & $0.0772^{+}$ \\
\hline Dyslipidemia, yes & $230(35.3)$ & $433(25.3)$ & $<0.0001^{+}$ \\
\hline Hypertension, yes & $444(68.2)$ & $1,168(68.3)$ & $0.9771^{+}$ \\
\hline \multicolumn{4}{|l|}{ Major events } \\
\hline \multicolumn{4}{|l|}{ All } \\
\hline Yes & $17(2.6)$ & $12(0.7)$ & $0.0002^{+}$ \\
\hline No & $634(97.4)$ & $1,699(99.3)$ & \\
\hline \multicolumn{4}{|l|}{ Stroke } \\
\hline Yes & $15(2.3)$ & $9(0.5)$ & $0.0001^{+}$ \\
\hline No & $636(97.7)$ & $1,702(99.5)$ & \\
\hline \multicolumn{4}{|l|}{ Systemic embolism } \\
\hline Yes & $1(0.2)$ & $1(0.1)$ & $0.4753^{\dagger}$ \\
\hline No & $650(99.8)$ & $1,710(99.9)$ & \\
\hline \multicolumn{4}{|l|}{ Death } \\
\hline Yes & $3(0.5)$ & $2(0.1)$ & $0.1321^{+}$ \\
\hline No & 648 (99.5) & 1,709 (99.9) & \\
\hline \multicolumn{4}{|l|}{ Major bleeding } \\
\hline Yes & $10(1.5)$ & $24(1.4)$ & $0.8078^{*}$ \\
\hline No & 641 (98.5) & 1,687 (98.6) & \\
\hline
\end{tabular}

Values are presented as mean \pm standard deviation or number (\%).

${ }^{*}$ Wilcoxon's rank sum test; ${ }^{+}$Chi-square test; ${ }^{*}$ Fisher's exact test.

Table 6. Comparison between patients with symptomatic ischemic stroke without cerebral atherosclerosis and patients without ischemic stroke

\begin{tabular}{|c|c|c|c|}
\hline Characteristic & $\begin{array}{l}\text { Patients with symptomatic ischemic stroke without the presence } \\
\text { of cerebral atherosclerosis (Department of Neurology) }(n=432)\end{array}$ & $\begin{array}{l}\text { Patients without symptomatic ischemic stroke } \\
\text { (Department of Cardiology) }(n=1,711)\end{array}$ & $P$ \\
\hline Age (yr) & $71.6 \pm 8.7$ & $70.0 \pm 10.4$ & $0.0137^{*}$ \\
\hline Male sex & $251(58.1)$ & $965(56.4)$ & $0.5315^{\dagger}$ \\
\hline Smoking history, yes & 70 (16.2) & $248(14.5)$ & $0.3794^{+}$ \\
\hline Diabetes, yes & $88(20.4)$ & $444(26.0)$ & $0.0165^{+}$ \\
\hline Dyslipidemia, yes & $151(35.0)$ & $433(25.3)$ & $<0.0001^{+}$ \\
\hline Hypertension, yes & $280(64.8)$ & $1,168(68.3)$ & $0.1712^{+}$ \\
\hline \multicolumn{4}{|l|}{ Major events } \\
\hline \multicolumn{4}{|l|}{ All } \\
\hline Yes & $7(1.6)$ & $12(0.7)$ & $0.0828^{+}$ \\
\hline No & $425(98.4)$ & 1,699 (99.3) & \\
\hline \multicolumn{4}{|l|}{ Stroke } \\
\hline Yes & $6(1.4)$ & $9(0.5)$ & $0.0962^{\dagger}$ \\
\hline No & $426(98.6)$ & $1,702(99.5)$ & \\
\hline \multicolumn{4}{|l|}{ Systemic embolism } \\
\hline Yes & $1(0.2)$ & $1(0.1)$ & $0.3626^{\dagger}$ \\
\hline No & 431 (99.8) & 1,710 (99.9) & \\
\hline \multicolumn{4}{|l|}{ Death } \\
\hline Yes & $2(0.5)$ & $2(0.1)$ & $0.1831^{\dagger}$ \\
\hline No & 430 (99.5) & 1,709 (99.9) & \\
\hline \multicolumn{4}{|l|}{ Major bleeding } \\
\hline Yes & $6(1.4)$ & $24(1.4)$ & $0.9826^{\dagger}$ \\
\hline No & 426 (98.6) & 1,687 (98.6) & \\
\hline
\end{tabular}

Values are presented as number (\%).

${ }^{*}$ Wilcoxon's rank sum test; ${ }^{+}$Chi-square test; ${ }^{\dagger}$ Fisher's exact test. 
with stroke were older and had a higher prevalence of dyslipidemia (Table 6).

\section{Discussion}

This study was a sub-analysis of data from 651 patients with AF-associated symptomatic stroke, who were treated with apixaban in the context of routine clinical practice, and additional MRI records. The $1.5 \%$ overall rate of major bleeding was broadly in line with previously reported clinical trial data in $\mathrm{AF}^{3,4}$ The rate of major events (stroke, systemic embolism, or death) over a mean treatment duration of 83 weeks was $2.6 \%$, similar to that observed in the ARISTOTLE trials, ${ }^{3,4}$ and a recent Japanese PMS study of apixaban following a similar methodology to the current study. ${ }^{10}$

An exploratory analysis of the present patient population showed that rates of major events, but not major bleeding, were higher in patients with symptomatic ischemic stroke than in those without. This result is similar with a sub-analysis of the Japanese PMS study, in which apixaban-treated AF patients with ischemic stroke or transient ischemic attack experienced significantly higher rates of thromboembolic and hemorrhagic events than those without. ${ }^{7}$ Since no independent risk factors for major events were identified in the secondary prevention group of the cited study, the authors simply stated that the increased event rates may be attributed to the prior ischemic stroke itself. ${ }^{7}$

In the current study, patients with stroke were older and more often had vascular risk factors such as hyperlipidemia or smoking than in those without, which may have contributed to the higher incidence of major events (Table 5). Additionally, MRI findings showed that the rate of major events or stroke was significantly increased in patients who had cerebral atherosclerotic lesions at baseline (Table 2). Because the differences in major events were not apparent when those cases were excluded (Table 6), the concomitant presence of cerebral artery atherosclerosis may, at least in part, be responsible for the increased rate of major events in patients with stroke than in those without.

A previous study showed that the presence of intracranial atherosclerosis is independently associated with the risk of subsequent vascular events in patients with ischemic stroke." Another study showed that the burden of systemic atherosclerosis, such as coronary and peripheral limb atherosclerosis, increased the occurrence of major adverse cardiovascular events, defined as a composite of stroke, coronary heart disease, and vascular death in patients with stroke and $\mathrm{AF} .{ }^{12}$ Finally, the $\mathrm{CHADS}_{2}$ score used for ischemic stroke risk stratification in pa- tients with nonvalvular AF also predicts the presence of concomitant cerebral artery atherosclerosis, and the elevated risk of stroke in patients with high $\mathrm{CHADS}_{2}$ scores may at least partly be explained by an increased burden of cerebral atherosclerosis. ${ }^{13}$ The present study confirms these previous arguments in the context of a well-monitored study in which all stroke patients with $\mathrm{AF}$ received apixaban.

Three of four patients (75.0\%) whose recurrent stroke was potentially related to large artery disease had cerebral artery atherosclerosis on initial imaging, while $55.6 \%$ of patients with recurrent stroke, probably due to cardiac embolism, had cerebral artery atherosclerosis. Due to the small number of patients who developed a recurrent stroke, it could not be clearly explored whether the recurrent strokes in these patients were primarily atherosclerotic in nature. Nevertheless, our results suggest that patients with atherosclerotic cerebral arteries are at an increased risk of recurrent stroke, and therefore, require more careful follow-up. Whether additional use of antiplatelet agents is needed in AF patients with concurrent cerebral atherosclerosis remains to be investigated.

WMH and microbleeds have been previously linked with an elevated risk of ischemic stroke or hemorrhage. ${ }^{14}$ In the current study, there was no increase in the risk of major events, stroke, or bleeding complications in patients with WMH, microbleeds, or aneurysms (Table 2). This is at odds with a previous study showing that the presence of SVD, defined as the presence of any of the following: $\geq 11$ basal ganglia perivascular space; $\geq 1$ microbleeds; $\geq 1$ lacunes; or moderate to severe WMH (Fazekas grade 3 in periventricular or grade 2 to 3 in deep area), was associated with increased occurrence of future ischemic stroke (hazard ratio, 1.89) in stroke patients using anticoagulation therapy. ${ }^{15}$ These results are not comparable with ours as the cited study used different definitions of SVD and enrolled patients receiving heterogeneous anticoagulants. Moreover, WMH or microbleeds per se were not associated with an increased risk of recurrent stroke in this study. However, the results of our current study may be inconclusive given the small number of patients with severe WMH or multiple microbleeds. Nevertheless, we cautiously suggest that apixaban administration in patients with mild SVD is likely to be safe in terms of bleeding complications.

An evaluation based on apixaban dosing found that the major bleeding rate was significantly higher in patients treated with an off-label reduced apixaban dose $(11.9 \%, P<0.0001)$. Furthermore, the rate of major events (stroke, systemic embolism, or death) in this group was higher than that in the overall population (3.4\% vs. $2.6 \%$, respectively), although the difference was not statistically significant. These data suggest a po- 
tential imbalance of effectiveness and safety in patients treated with a lower apixaban dose than recommended. Previous studies have also suggested that off-label reduced dosing of NOACs may be linked with increased stroke risk ${ }^{15,16}$ or hemorrhagic events. ${ }^{17}$ Hence, non-adherence with on-label dose recommendations may have clinical consequences. However, the results of this observational study may be confounded by the characteristics of individual patients; the charged physicians may have used a lower dose because they felt the patients were at a higher bleeding risk. Thus, further controlled studies are required to arrive at a more definitive conclusion.

There are some limitations to this study. First, this was a single-arm observational study without a control group, performed in the context of routine practice. This inevitably limits the value of the safety and effectiveness data in this study. Second, this sub-analysis was based on patients with additional MRI records, and thus reducing the population size and the number of patients who experienced major events. Therefore, the results obtained here should be interpreted with caution. Finally, in this multicenter, practical study, MRI technologies were not homogeneous, and imaging findings were interpreted by local investigators.

\section{Conclusions}

Our results showed that the effectiveness and safety of apixaban for reducing the risk of stroke and systemic embolism in Korean patients with AF in routine clinical practice was consistent with the results of the ARISTOTLE trial. MRI data from this population showed that the rate of stroke was significantly increased in patients with cerebral artery atherosclerosis, suggesting that special care is required in these individuals. Off-label reduced dosing may be associated with worse outcomes, and thus compelling the use of on-label recommended dosing in real-life practice.

\section{Supplementary materials}

Supplementary materials related to this article can be found online at https://doi.org/10.5853/jos.2021.02355.

\section{Disclosure}

This study was funded by Pfizer Inc. and Bristol Myers Squibb and conducted by Bristol Myers Squibb Korea.

Jong S. Kim reports receiving grants from Dong-A, Pfizer, Servier, Daiichi-Sankyo, and Shin-Poong outside of the submitted work. Keun-Sik Hong reports receiving grants from Bristol
Myers Squibb (BMS) Korea Ltd. during the conduct of the study, grants from BMS Korea, Boryung Pharmaceutical, and Hanmi Pharm outside of the submitted work, and lecture honoraria from BMS Korea and Daiichi Sankyo Korea outside of the submitted work. Hyeju Yi is an employee of Bristol Myers Squibb, Korea. The authors have no conflicts of interest to declare.

\section{Acknowledgments}

We thank all 23 institutions and co-investigators who actively participated in this study. Medical writing and editorial support were provided by Soyoung Park of PPC Korea and Cathy Chow, PhD, of Weber Shandwick Hong Kong.

\section{References}

1. Steffel J, Verhamme P, Potpara TS, Albaladejo P, Antz $M_{1}$ Desteghe L, et al. The 2018 European Heart Rhythm Association practical guide on the use of non-vitamin $\mathrm{K}$ antagonist oral anticoagulants in patients with atrial fibrillation. Eur Heart J 2018;39:1330-1393.

2. Joung $B$, Lee JM, Lee KH, Kim TH, Choi EK, Lim WH, et al. 2018 Korean guideline of atrial fibrillation management. Korean Circ J 2018;48:1033-1080.

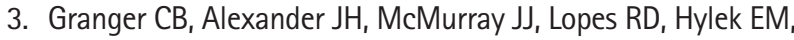
Hanna $M$, et al. Apixaban versus warfarin in patients with atrial fibrillation. N Engl J Med 2011;365:981-992.

4. Goto S, Zhu J, Liu L, Oh BH, Wojdyla DM, Aylward P, et al. Efficacy and safety of apixaban compared with warfarin for stroke prevention in patients with atrial fibrillation from East Asia: a subanalysis of the Apixaban for Reduction in Stroke and Other Thromboembolic Events in Atrial Fibrillation (ARISTOTLE) Trial. Am Heart J 2014;168:303-309.

5. Kirchhof $P$, Benussi $S$, Kotecha D, Ahlsson A, Atar D, Casadei $B$, et al. 2016 ESC guidelines for the management of atrial fibrillation developed in collaboration with EACTS. Eur J Cardiothorac Surg 2016;50:e1-e88.

6. Park J, Lee SR, Choi EK, Kwon S, Jung JH, Han KD, et al. Effectiveness and safety of direct oral anticoagulant for secondary prevention in Asians with atrial fibrillation. $J$ Clin Med 2019;8:2228.

7. Yasaka $M$, Umeyama $M$, Kataoka $H$, Inoue $H$. Secondary stroke prevention with apixaban in nonvalvular atrial fibrillation: a subgroup analysis of the STANDARD study. J Stroke Cerebrovasc Dis 2020;29:105034.

8. Das AS, Regenhardt RW, Vernooij MW, Blacker D, Charidimou A, Viswanathan A. Asymptomatic cerebral small vessel dis- 
ease: insights from population-based studies. J Stroke 2019; 21:121-138.

9. Fazekas F, Chawluk JB, Alavi A, Hurtig HI, Zimmerman RA. MR signal abnormalities at $1.5 \mathrm{~T}$ in Alzheimer's dementia and normal aging. AJR Am J Roentgenol 1987;149:351-356.

10. Inoue $H$, Umeyama $M$, Yamada $T$, Hashimoto $H$, Komoto $A$, Yasaka M. Safety and effectiveness of apixaban in Japanese patients with nonvalvular atrial fibrillation in clinical practice: a regulatory postmarketing surveillance, the STANDARD study. J Arrhythm 2019;35:506-514.

11. Kim BS, Chung PW, Park KY, Won HH, Bang OY, Chung CS, et al. Burden of intracranial atherosclerosis is associated with long-term vascular outcome in patients with ischemic stroke. Stroke 2017;48:2819-2826.

12. Park JH, Chung JW, Bang OY, Kim GM, Choi KH, Park MS, et al. Atherosclerotic burden and vascular risk in stroke patients with atrial fibrillation. Stroke 2021;52:1662-1672.

13. Kim YD, Cha MJ, Kim J, Lee DH, Lee HS, Nam CM, et al. In- creases in cerebral atherosclerosis according to CHADS2 scores in patients with stroke with nonvalvular atrial fibrillation. Stroke 2011;42:930-934.

14. Kim BJ, Lee SH. Prognostic impact of cerebral small vessel disease on stroke outcome. J Stroke 2015;17:101-110.

15. Du H, Wilson D, Ambler G, Banerjee G, Shakeshaft C, Cohen $\mathrm{H}$, et al. Small vessel disease and ischemic stroke risk during anticoagulation for atrial fibrillation after cerebral ischemia. Stroke 2021;52:91-99.

16. Steinberg BA, Shrader $P$, Thomas $L$, Ansell J, Fonarow GC, Gersh BJ, et al. Off-label dosing of non-vitamin $\mathrm{K}$ antagonist oral anticoagulants and adverse outcomes: the ORBIT-AF II Registry. J Am Coll Cardiol 2016;68:2597-2604.

17. Bassand JP, Virdone $S$, Badoz M, Verheugt F, Camm AJ, Cools $F$, et al. Bleeding and related mortality with NOACs and VKAs in newly diagnosed atrial fibrillation: results from the GARFIELD-AF registry. Blood Adv 2021;5:1081-1091. 
Appendix 1. Additional data sheet

10. Initial stroke admission note

1. Did your patient have symptomatic ischemic stroke?

$\square$ Yes ( $\square$ Single event / $\square$ Multiple) $\square$ No

Mechanism (by TOAST criteria, multiple choice):

$\square \mathrm{LAD} \square \mathrm{CE} \square \mathrm{SVD} \square$ Undetermined $\square$ Other determined $\square$ Unknown

\begin{tabular}{|c|c|c|}
\hline \multirow[t]{3}{*}{ 2. MRI } & DWI & $\begin{array}{l}\square \text { Cortico-subcortical } \square \text { Cortical } \\
\square \text { Subcortical or brainstem ( } \square \leq 15 \mathrm{~mm} / \square>15 \mathrm{~mm}) \\
\square 1 \text { vessel territory } \square \text { More than } 1 \text { vessel territory }\end{array}$ \\
\hline & GRE, FLAIR & $\begin{array}{ll}\text { Microbleeds: } & \square \text { Yes }(\square \geq 5 \square<5) \quad \square \text { No } \\
\text { Hemorrhagic transformation: } \quad \square \text { Yes ( } \square \mathrm{HI} 1 \square \mathrm{HI} 2 \square \mathrm{PH} 1 \square \mathrm{PH} 2) \text { (Fiorelli 1999) } \square \text { No } \\
\text { White mater ischemic change: Fazeka's scale }(\square 0 \square 1 \square 2 \square 3)\end{array}$ \\
\hline & $\begin{array}{l}\text { Angiography (CTA, MRA, } \\
\text { TFCA) }\end{array}$ & $\begin{array}{l}\text { Is there an aneurysm? } \square \text { Yes } \square \text { No } \\
\text { Can you observe atherosclerotic steno-occlusion? } \square \text { Yes } \downarrow \text { (Please check below.) } \square \text { No } \\
\rightarrow \text { Atherosclerosis related to the infarct: } \square \text { Intracranial } \square \text { Extracranial } \square \text { Both } \\
\rightarrow \text { Atherosclerosis unrelated to the infarct: } \square \text { Intracranial } \square \text { Extracranial } \square \text { Both } \\
\rightarrow \text { Do both atherosclerosis (related/not related to the infarct) exist? } \square \text { Yes } \square \text { No }\end{array}$ \\
\hline
\end{tabular}

3. Is there a possibility that this stroke event is small vessel disease?

$\square$ Yes $\square$ No

4. Laboratory test data at the time of stroke event.

\begin{tabular}{|c|c|c|c|c|c|c|c|}
\hline Test Item & Test Date & Test Result & Normal range & Test Item & Test Date & Test Result & Normal range \\
\hline WBC & & $10^{3} / \mathrm{uL}$ & & $\mathrm{Hb}$ & & $\mathrm{g} / \mathrm{dL}$ & \\
\hline Platelet & & $10^{3} / \mathrm{uL}$ & & PT & & & \\
\hline \multirow[t]{2}{*}{ CRP } & & $\mathrm{mg} / \mathrm{dL}$ & & INR & & & \\
\hline & & & & d-dimer & & $\mathrm{ug} / \mathrm{mL}$ & \\
\hline
\end{tabular}

5. Echocardiography result

(If test result 3 months before/after hospitalization exists, answer to the questions below. If there are several test results, please choose the result closest to the stroke event.)

Was Echocardiography conducted? $\square$ Yes $\downarrow$ (Please check below.) $\square$ No

$\rightarrow$ LV Ejection Fraction: ( ） ）

$\rightarrow$ Valvular abnormalities (in case of trace, please check "No")

Mitral valve regurgitation $\square$ Yes, $\operatorname{Gr}(\square 1 \square 2 \square 3 \square 4$ or $\square$ mild $\square$ moderate $\square$ severe $) \square$ No

Mitral valve stenosis $\square$ Yes, MVA (2D/PHT): $(\quad / \quad) \mathrm{cm}^{2} \square$ No

Aortic valve regurgitation $\square$ Yes, $\operatorname{Gr}(\square 1 \square 2 \square 3 \square 4$ or $\square$ mild $\square$ moderate $\square$ severe $) \square$ No

Aortic valve stenosis $\square$ Yes, AVA (2D/Doppler): ( / ) $\mathrm{cm}^{2} \square$ No

LA diameter ( ) $\mathrm{mm}$

[Major Event Occurrence Status]

Please fill in the below events until the end of study. 


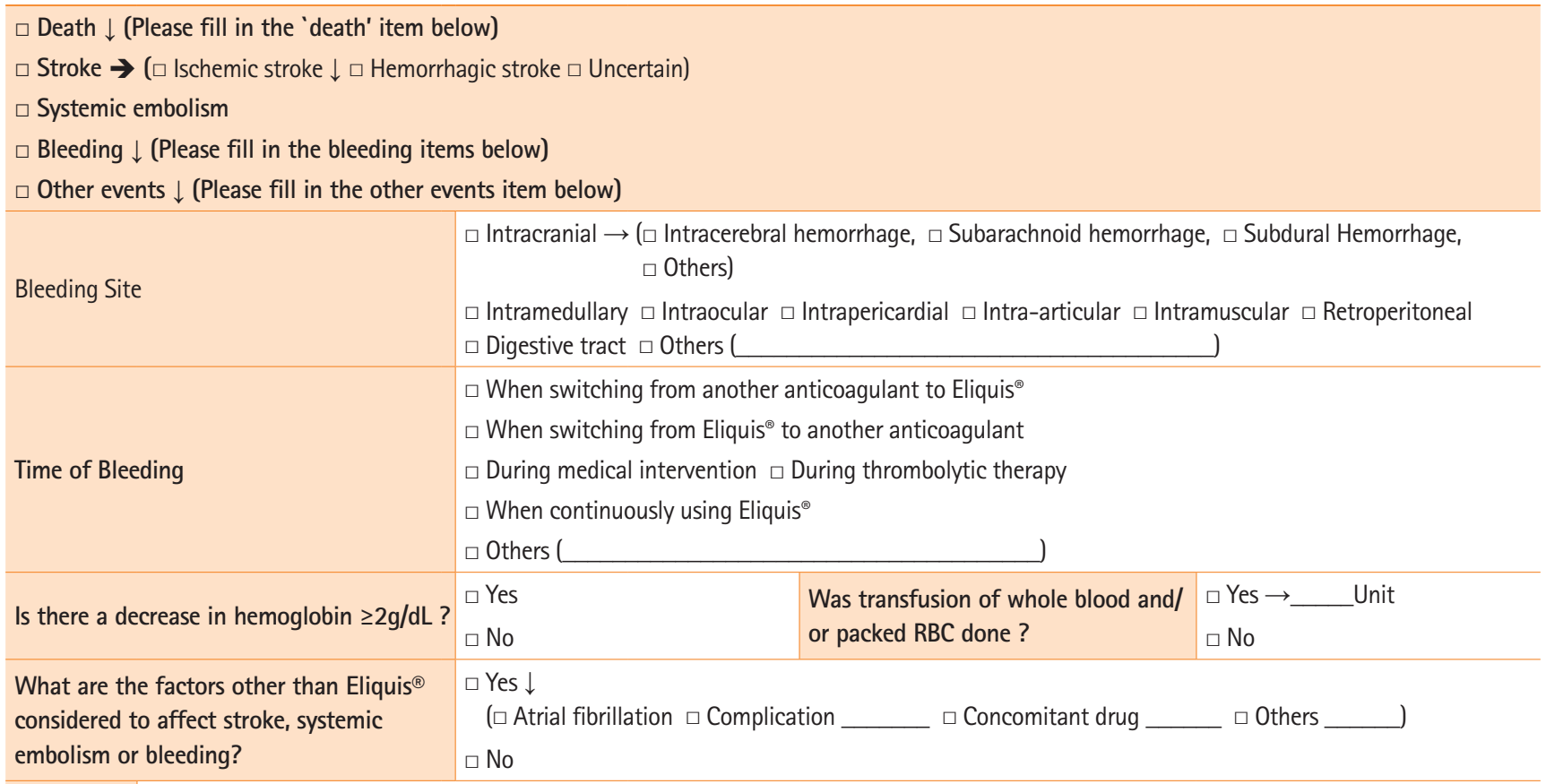

\begin{tabular}{|c|c|c|c|c|c|c|}
\hline \multirow{10}{*}{$\begin{array}{l}\text { Ischemic } \\
\text { stroke }\end{array}$} & \multicolumn{6}{|c|}{$\begin{array}{l}\text { 1. Can you assess patient's status? } \\
\square \text { Yes } \downarrow \text { (Please fill in the below.) } \square \text { No (assessment is not feasible due to transfer to another hospital, etc.) } \\
\text { 2. Neurologic status } \\
\square \text { Admission NIHSS } \square \text { Admission mRS } \square \text { Discharge NIHSS } \square \text { Discharge mRS }\end{array}$} \\
\hline & \multirow{3}{*}{ 3. MRI } & \multirow[t]{2}{*}{ 3-1. DWI } & \multicolumn{4}{|c|}{$\begin{array}{ll}\text { Single lesion: } & \square \text { Cortico-subcortical } \square \text { Cortical } \\
& \square \text { Subcortical or brainstem }(\square \leq 15 \mathrm{~mm} / \square>15 \mathrm{~mm})\end{array}$} \\
\hline & & & \multicolumn{4}{|c|}{ Multiple scattered: $\square 1$ vessel territory $\square$ More than 1 vessel territory } \\
\hline & & 3-2. GRE, FLAIR & \multicolumn{4}{|c|}{$\begin{array}{l}\text { Compared to previous image, were microbleeds increased? } \square \text { Yes } \square \text { No } \\
\text { Hemorrhagic transformation: } \square \text { Yes ( } \square \mathrm{HI} 1 \square \mathrm{HI} 2 \square \mathrm{PH} 1 \square \mathrm{PH} 2) \square \text { No }\end{array}$} \\
\hline & \multicolumn{6}{|c|}{$\begin{array}{l}\text { 4. Is there a possibility that this stroke event is due to large artery disease? } \\
\square \text { Yes } \square \text { No } \\
\text { 5. Is there a possibility that this stroke event is due to small vessel disease? } \\
\square \text { Yes } \square \text { No } \\
\text { 6. Laboratory Test Data at the time of stroke event. }\end{array}$} \\
\hline & Test item & Test date & Test result & Test item & Test date & Test result \\
\hline & WBC & & $10^{3} / \mathrm{uL}$ & $\mathrm{Hb}$ & & $\mathrm{g} / \mathrm{dL}$ \\
\hline & Platelet & & $10^{3} / \mathrm{uL}$ & PT & & \\
\hline & \multirow[t]{2}{*}{ CRP } & & $\mathrm{mg} / \mathrm{dL}$ & INR & & \\
\hline & & & & d-dimer & & $\mathrm{ug} / \mathrm{mL}$ \\
\hline \multicolumn{2}{|l|}{ Death } & \multicolumn{5}{|c|}{$\begin{array}{l}\square \text { VTE-related death } \\
\square \text { Non VTE-related cardiovascular death } \\
\square \text { Death related to myocardial infarction } \\
\square \text { Death related to stroke } \\
\square \text { Death related to cardiovascular disease } \\
\square \text { Death related to major bleeding }\end{array}$} \\
\hline \multicolumn{2}{|c|}{ Other events } & \multicolumn{5}{|c|}{$\square$ Other cardiovascular disease $;$} \\
\hline \multicolumn{2}{|c|}{$\begin{array}{l}\text { Was intervention or medication given for } \\
\text { the major event? }\end{array}$} & \multicolumn{5}{|c|}{$\begin{array}{l}\square \text { Yes } \rightarrow \text { Please describe the detail in the "Medical Intervention, Medication of Anticoagulant other than } \\
\text { Eliquis }{ }^{\circledast} \text {, Concomitant Medication Status" section. } \\
\square \text { No }\end{array}$} \\
\hline
\end{tabular}

